\title{
Online Satın Alma Davranışında Genel Erteleme, Algılanan Risk, Akış Deneyimi ve Online Ertelemenin Rolüne İlişkin Bir Model Testi
}

\author{
A Model Test On The Role Of General Procrastination, Perceived Risk, Flow \\ Experience And Online Procrastination In Online Purchasing Behavior
}

\author{
Özsev BERK * \\ Remzi ALTUNIŞIK ** \\ Nilgün SARIKAYA ***
}

\begin{abstract}
$\ddot{O} Z$
Bu çalışmada, online satın alma davranışında genel erteleme eğilimi, akış deneyimi, online erteleme eğilimi ve algılanan risk kavramlarının rolünü ortaya koymaya çalışan bir model test edilmektedir. Araştırma bağlamında kolayda örnekleme yöntemi ile seçilmiş 551 katılımcı üzerinde yapılan anketten elde edilen veriler kullanılmıştır. Verilerin analizinde SmartPLS 3.2.9 programı kullanılmıştır.

Araştırma bulgularına göre genel erteleme ve online erteleme eğiliminin online satın alma davranışında etkisinin negatif olmadığg; erteleme eğilimli kişilerin online erteleme, alışveriş keyfi, tele bulunma boyutlarına etkisinin pozitif olduğunu ortaya koymaktadır. Online erteleme eğiliminin, tele bulunma ve alışveriş keyfi boyutlarında pozitif etkisi olduğu gözlenmişstir. Ancak algllanan riskin online erteleme üzerinde negatif etkisi desteklenmemiştir.
\end{abstract}

\section{ANAHTAR KELIMELER}

Genel Erteleme Eğilimi, Online Erteleme Eğilimi, Akış Deneyimi, Algılanan Risk, Online Satın Alma Davranışı

\begin{abstract}
In this study, a model that tries to reveal the role of general procrastination, flow experience, online procrastination and perceived risk in online purchasing behavior is tested. In the context of the research, the data obtained from the survey conducted on 551 participants selected by convenience sampling method were used. SmartPLS 3.2.9 program was used in the analysis of the data.
\end{abstract}

According to the research findings, the effect of general procrastination and online procrastination on online purchasing behavior is not negative; It reveals that the procrastination prone people have a positive effect on online procrastination, shopping pleasure, and telepresence. It has been observed that the tendency to procrastinate online has a positive effect on the dimensions of tele presence and shopping pleasure.However, the negative effect of perceived risk on online procrastination is not supported.

\section{KEYWORDS}

General Procrastination, Online Procrastination, Flow Experience, Perceived Risk, Online Purchase Behaviour.

\begin{tabular}{|c|c|c|}
\hline \multicolumn{2}{|r|}{$\begin{array}{c}\text { Makale Geliş Tarihi / Submission Date } \\
04.08 .2021\end{array}$} & $\begin{array}{c}\text { Makale Kabul Tarihi / Date of Acceptance } \\
01.11 .2021\end{array}$ \\
\hline Atıf & $\begin{array}{l}\text { Berk, Ö., Altunışık, R. ve Sarıkaya, N. } \\
\text { Deneyimi ve Online Ertelemenin Ro } \\
\text { Yüksekokulu Dergisi, } 24 \text { (2), 485-498. }\end{array}$ & $\begin{array}{l}\text { lma Davranışında Genel Erteleme, Algılanan Risk, Akış } \\
\text { lel Testi. Selçuk Üniversitesi Sosyal Bilimler Meslek }\end{array}$ \\
\hline
\end{tabular}

\footnotetext{
* Sakarya Üniversitesi, ozsewaliskann@hotmail.com, ORCID: 0000-0002-1314-9125

** Prof. Dr., Sakarya Üniversitesi, altunr@sakarya.edu.tr, ORCID: 0000-0001-7934-1841

*** Prof. Dr., Sakarya Üniversitesi, nilguns@sakarya.edu.tr, ORCID: 0000-0002-1696-4950
} 


\section{GİRIŞ}

Yazında daha çok bir kişilik özelliği olarak tanımlanan erteleme eğilimi (procrastination) kavramı ağırlıklı olarak akademik çalışmalardaki erteleme davranışlarında ele alınan bir kavram olarak karşımıza çıkmaktadır. Kavramın Türkçe karşılığına ilişkin literatürde erteleme, geciktirme, savsaklama, vb. değişik kelimeler kullanılmıştır. Bu çalışmada kavramın karşılığı olarak erteleme kelimesi kullanılmaktadır. Erteleme sadece öğrencilerin ödevleri geç teslim etmesi veya akademik çalışmaların belirli bir gerekçe olmaksızın ertelenmesi veya sonraya bırakılması ile ilgili bir kavram olmayıp yaşamımızın hemen her aşamasında değişik şekillerde zuhur edebilmektedir. Örneğin, bir faturanın ödenmesinin genellikle son ana bırakılması, alışverişlerde kararsızlık veya başka sebeplerle ürün satın almaksızın mağazanın terk edilmesi, alışverişlerde içi ürün dolu alışveriş arabasının ortada bırakıp mağazayı terk etme, online alışverişlerde ürünü sepete koyduktan sonra alışveriş sürecinin günlerce veya haftalarca tamamlanmaması, almanız gereken bir doktor randevusunun anlamsız bir şekilde son ana bırakılması ve hatta bu yüzden sıkıntıya girilmesi, vb. daha birçok davranış bu olgunun ne derece yaygın olduğunun bir göstergesidir. Bu davranışın sadece belirli demografik gruba ait kişilere özgün bir davranış olmadığ toplumun hemen her kesiminde kişilerde karşılaşılabileceği açıktır.

Erteleme eğilimi teknolojinin gelişmesiyle birlikte hayatımıza daha fazla girmeye başlayan internet, bilgisayar, akıllı telefon, tablet gibi araçlarla birlikte daha da sık karşılaşılabilen bir davranış olarak karşımıza çıkmaktadır. Bu da erteleme eğiliminin yeni hali olarak düşünülebilecek olan online erteleme eğilimini gündeme getirmektedir. Online ertelemede kişiler, sıkıcı, hoş olmayan ve zorlayıcı günlük işlerden veya akademik süreçle ilgili görevlerden kaçınmak için internet tabanlı dijital uygulamalar ve diğer sosyal medya araçlarına yönelmektedirler (Thatcher vd., 2008). Bireyler bu deneyimi geleneksel erteleme davranışı (işi bırakıp arkadaşlarla buluşma, televizyon izleme, alışverişe çıkma, ortam değiştirme) yerine, harekete geçmeye veya mekânsal değişikliğe gerek kalmaksızın bulundukları mekân, zaman ve durumda birkaç tuşa dokunmakla geçebildiklerinden özellikle gençler arasında hızlı yayılmaktadır.

$\mathrm{Bu}$ çalışmada erteleme eğiliminin tüketicilerin satın alma davranışları üzerinde etkisinin olup olmadığı sorusu üzerinde durulmaktadır. Özellikle de günümüzde giderek daha da yaygınlaşmaya başlayan e-ticaret ve online alışveriş davranışları açısından erteleme eğiliminin rolüne ilişkin çeşitli öneriler ve açıklamalar yazında öne çıkmaktadır.

Genel alan yazında erteleme eğilimli kişilerin, interneti hoş olmayan görevlerden veya kararlardan kaçınma amacıyla kullanma eğiliminde oldukları belirtilmektedir. Genellikle de internet bu kaçış yolunun 1şığı olarak algılanmaktadır. İnternet kullanımı erteleme için yer değiştirmeden, hızlı, eğlenceli ve dikkat dağıtmada arzu edilen etkili bir araç olmaktadır (Lavoie ve Pychyl, 2001). Bu süreç online erteleyicilerin akış deneyimine katılımıyla sağlamakta olduklarına işaret etmektedir. Literatürde akış deneyimi, öznel bir durum olarak tanımlanmakta olup, kişinin (süregelen faaliyetinin dışında zaman, yorgunluk ve her şeyi unutarak) bir şeye karışması veya dalıp gitmesi durumu olarak tanımlanmaktadır (Csikzentmihalyi, 1975). Akış deneyimi daha çok olumlu duygular ve ruh hali ile ilişsilidir (Chen, 2006). Online erteleme eğilimindeki kişilerin akış deneyimini zevkli ve memnuniyet verici gördükleri için mümkün olduğunca söz konusu davranışı sıksık tekrarlama eğiliminde oldukları ifade edilmektedir (Huang, 2014;O’Cass ve Carlson, 2010).

İnsanlar tüm davranışlarında olduğu gibi alışveriş davranışlarında da riskten kaçınma yoluna gitmektedirler. Online alışverişlerde de kişilerin online ortama has sebeplerden dolayı risk algısı içine girdikleri gözlenmektedir. Acaba kişilerin erteleme eğiliminin sebeplerinden birisi de algılanan risk olabilir mi sorusunu akla getirmektedir. Bundan hareketle, erteleme eğilimli kişilerin yaşadıkları olumsuz duyguları yok etme amacıyla girdikleri online süreçte, satın alma davranışına yönelmeleri olası bir durum olmaktadır. Çünkü satın alma ve tüketim bireylerde olumlu duygu yaratmada en etkin davranış olarak görülmektedir (Garg vd., 2007). Ayrıca, geleneksel satın almadan farklı olarak online satın almada algılanan riskler mevcuttur. Algılanan risk, bir kayıp olasılığını ve olumsuz sonuçların kişide yarattığı hissi ifade etmektedir (Cunnigham, 1967). Online erteleme, internetin eğlenceli olacağını düşünerek erteleyenlerin, bir görevi erteleyerek, hoş buldukları, olumlu duyguları hissedecekleri faaliyetlerde bulunmayı tercih edeceklerini göstermektedir (Ellis \& Knaus, 1977; Mcknown ve Jhonson, 1989). Bu bağlamda algılanan risk kavramının erteleme eğilimli kişilere karşı etkisi de araştırmada değerlendirmeye alınacaktır.

Diğer bir taraftan bakıldığında, çevrimiçi perakendecilerin müşterilerini web tabanlı mağazaları ziyaret etmeye ikna etmek için önemli miktarda çaba sarf etmekte ve para harcamaktadır (Cho, 2004). Çoğu firma, web sitesi trafiğinin yalnızca \%2-3'ünün satın almayla sonuçlanabileceğinin farkındadır (Li ve Chatterjee, 2005). Çeşitli e-ticaret web sitelerinde alışveriş sepetinden vazgeçme oranı \%20 ile 90 arasında değişmektedir (ScanAlert, 2005). En başarılı işletmeciler, bunun yalnızca \%8'ini satın almaya dönüştürmüştür (Li ve Chatterjee, 2005). Bu bilgiler değerlendirildiğinde pazarlamacılar ve işletmeciler tarafından online satın alma 
davranışındaki başarı oranının artırılması adına erteleme eğilimli kişilerin hedef kitle olarak baz alınmasında fayda vardır. Bu kişilerin yeni hedef kitle anlayışına uyarlanması, onlara yönelik tutundurma stratejilerinin geliştirilmesi rakipleriyle arasında rekabet gücünü yükseltecektir.

$\mathrm{Bu}$ çalışmada, genel erteleme davranışı, akış deneyimi, online erteleme davranışı ve algılanan risk kavramlarının online satın alma davranışına etkisini ortaya koyan bir model test edilmeye çalış1maktadır. Çalışmanın modelinde kullanılan tüm kavramlara kavramsal çerçevede değinilecektir. Kavramlar seçilirken online satın almada erteleme eğilimi ve online ertelemenin etkisine ilişkin değişkenler baz alınmıştır. Online ertelemenin oluşumuna ve online satın almaya geçişi akış deneyimi ve online satın almayı en çok etkileyen algılanan riskler değerlendirilmeye çalışılmıştır. Ayrıca model de kullanılan kavramlar farklı çalışmalarda incelenmiş olup yeni bir farkındalık geliştirmek açısından tasarlanmıştır. Ayrıca genel erteleme, online erteleme davranışı ve akış deneyimi kavramları psikoloji disiplinine ait olup multidisipliner yaklaşımla pazarlama alanında pazarlamacılara, pazardaki yeni hedef kitle oluşumuna, e-ticarette yeni tüketici yaklaşımına, işletmecilerin rekabet gücünün artmasına ve potansiyel tüketicilerin farkındalıklarına katkı sağlayacağı düşünülmektedir.

\section{KAVRAMSAL ÇERÇEVE}

Bu bölümde araştırmada kullanılan genel erteleme eğilimi,akış deneyimi,online erteleme, algılanan risk ve online satın alma davranışı kavramları ele alınarak bir kavramsal çerçeve oluşturulacaktır.

Genel Erteleme Davranışı, hayatın her alanında hemen hemen herkeste görülen çok boyutlu bir olgudur. Alan yazında kavrama yönelik çeşitli tanımlamalar mevcuttur. Örnek olarak; Lay (1986) önemli işlere başlamayı ve bu işleri geciktirme eğilimi olarak tanımlamaktadır. Solomon ve Rothblum, (1984) erteleyen kişinin, sonunda huzursuzluk duyacağı noktaya kadar işleri ertelemesi şeklinde belirtmiştir.

Akış Deneyimi, bireyin amaçlarını gerçekleştirmek için, dikkatini bütünüyle yaşadığı deneyime vermesini ve bu deneyimden mutluluk duymasını ifade etmektedir. Akış, bireylerin bir etkinliğe kendilerini başka hiçbir şeyi umursamayacak kadar kaptırmalarıdır. Bu yaşantı kendi başına öyle keyiflidir ki bireyler sırf o etkinlikte bulunmak için bile büyük bir bedel ödeyebilmektedirler (Csikzentmihalyi, 1990). Ayrıca akış deneyimi, kişinin becerisinin tam olarak ilgili faaliyette yararlı, bu becerinin faaliyetin taleplerine eşit, içsel motivasyonun en üst düzeyde, kişinin kendi bilincini ve zamansal farkındalığını yitirdiği, tam kontrol, zahmetsizlik ve o anki durumla ilgili bir dikkat toplaşımı olduğu zaman ortaya çıkar (https:// dictionary.apa.org/, 7.11.2018). Araştırmada akış deneyimini ölçmek için dört boyut kullanılmıştır. Alışveriş keyfi(zevk), konsantrasyon, tele bulunma(öz bilinç kaybı) ve zaman çarpıklı̆̆ıdır. Alışveriş keyfi,yaygın bir akış ölçüsü olup bir çevre aktivitesinin içsel zevk seviyesidir (Novak vd., 2000). Konsantrasyon, akış içerisine giren bireylerin faaliyetlerine odaklanmaları için gerekli ve olması gereken bir ölçüdür. Özellikle online ve online satın alma sürecinde çok fazla dikkat dağıtıcı unsurlar (telefon sesi, televizyon sesi, çocukların istekleri vb.) bulunmaktadır. Öz bilinç kaybı,(telepresence) Bir etkinlik, bireyi tam olarak içerisine aldığında, geçmişi ya da geleceği veya zamansal olarak ilgisiz herhangi bir uyaranı düşünmeye yetecek kadar dikkati kalmamaktadır. Bu farkındalıktan kaynaklı " benlik" duygusu ortaya çıkmaktadır (Csikzentmihalyi, 1990). Zaman Çarpıkliğı, büyük bir hızla ya da aşırı yavaşlık ile geçtiği görülen, değişen bilinç durumlarında deneyimlenen bir tür algısal dönüşümü ifade etmektedir (https:// dictionary.apa.org / time- distortion, 08.09.2019).

Online Erteleme Eğilimi, kişilerin interneti hoş olmayan görevlerden veya kararlardan kaçınma amacıyla kullanma eğilimini ifade eder. Erteleme araçları internettir. Çevrimiçi erteleyiciler genellikle interneti sıkıcı, hoş olmayan veya çok zorlayıcı görevlerden kaçınmak için kullanırlar (Thatcher vd., 2008). Bu nedenle memnuniyet verici çevrimiçi dikkat dağıtıcıları arama eğilimindedirler.

Silver ve Sabini (1981) erteleme teorisine göre, erteleme eğilimli kişiler bir göreve doğru çalışmayı geciktirmek için zamanın kısa aralıklarla bölünmesini ifade etmektedir. Özelilikle e-postalara bakma, web'de gezinmek vb. internet etkinlikleri çekici olmaktadır. Bu etkinlikler hızlı, anında ödüllendirici ve istenildiği zaman durdurulmaktadir.

Algılanan Risk ve online satın alma davranışı, Cox ve Rich (1964) tüketicilerin yapmış oldukları satın alımların beklentilerini karşılamama şeklinde tanımlamışlardır. Tüketiciler internetten alışveriş yaptıklarında geleneksel alışverişle kıyaslandığında daha fazla risk algılamaktadırlar (Lee ve Tan, 2003). Araştırmada algılanan risk kavramının üç türü baz alınacaktır. Bunlar: finansal, ürün, zaman/kolaylık riskleridir. Finansal risk, mali kayıp yaşama olasıllğı olarak nitelendirilmektedir (Horton, 1984). ～Ürün riski, tüketicinin sipariş etmiş olduğu ürün beklentisi ile ürünün beklentileri karş1layabilmesi arasındaki farlılıkları ifade etmektedir (Peter ve Tarpey, 1975). Zaman riski, çevrimiçi alışverişlerde yaşanan stresi, genellikle erişilebilirlik, istek 
gönderme veya erteleme maddelerini kabul etmekten kaynaklanan sıkıntıları içermektedir (Forsythe vd., 2006).

\subsection{Değişkenler Arasındaki İlişskiler}

\subsubsection{Genel Erteleme Davranışı ve Akış Deneyimi Arasındaki İlişkiler}

Literatür incelemesine göre erteleme ve akış üzerindeki araştırmalarda akış deneyiminin oluşmasında genel ve akademik erteleme kavramlarının öncü olduğu belirtilmiştir (Kim ve Seo, 2015; Uzun, 2014). Erteleme eğilimi gösteren bireyler sıkıcı, zor görevlerini erteledikleri için kaygı, stres gibi olumsuz duygular yaşamaktadırlar. Erteleme eğilimi, akış sırasında yaşanan zevk ve kaygı azalması sebebiyle olumsuz duyguları hafifletmek için çevrimiçi akış deneyimi yaşamaya açık olmaktadırlar.

\subsubsection{Algılanan Risk ve Akış Deneyimi Arasındaki İlişkiler}

Online platformlarda tüketicilerin karşılaştığı riskler ve psikolojik (akış deneyimi) durum satın alma bağlamında hedefine etki etmektedir. Çevrimiçi ortamlarda, algılanan riskin en önemli negatif durum olduğu saptanmıştır (Shaw ve Sergueeva, 2019). Costa ve Lucian (2014) yaptıkları araştırmada çevrimiçi tüketicinin yeteneklerini baz aldıklarında, tüketici riski ne kadar az algılarsa akış deneyiminin gerçekleşmesinin daha yüksek olacağını saptamışlardır.

\subsubsection{Genel Erteleme ve Online Erteleme Arasındaki İlişkiler}

Teknolojinin gelişmesi, internetin telefonlarda, evde, işyerinde hayatımızın her alanına yayılması sebebiyle literatüre online(çevrimiçi) erteleme kavramı girmiştir. Hen ve Gorosit (2018) yaptıkları çalışmada karar vermede ve genel erteleme eğilimi gösteren katılımcıların yüksek seviyede online erteleme eğilimi ile pozitif ilişkili olduğunu ortaya koymuş̧tur. Lavoie ve Pychyl (2001) yaptıkları araştırmada internete olan tutum, online olarak geçirdikleri süre (evde, okulda, işte) genel erteleme eğiliminin pozitif ve negatif duygu durumları ile ölçülmüştür. Sonucuna göre katılımcıların \%50,7'si internette erteleme eğilimi ve \%47'online zamanlarını erteleyerek geçirdiğini göstermektedir. Chen (2006) araştırmasında genel erteleme eğilimi ve online erteleme arasında pozitif ilişki olduğunu ortaya çıkmıştır.

\subsubsection{Akış Deneyimi ve Online Erteleme Arasındaki İlişsiler}

Akış deneyimi, olumlu duygular ve ruh hali ile ilişkilidir (Chen, 2006). Thatcher vd. (2008) Güney Afrika örneğinde teknoloji çalışanları ile diğer çalışanlar arasında sorunlu internet kullanımının yaygınlığını ve ilişkileri araştırılmıştır. Yapılan araştırmaya göre online erteleme ve akış deneyimi arasında pozitif bir ilişki bulunmuştur.

\subsubsection{Algılanan Risk ve Online Erteleme Arasındaki İlişskiler}

Algılanan risk, online (çevrimiçi) erteleme için de önemli bir faktördür. Online erteleme eğilimindeki bireyler internetin eğlenceli olacağını, olumlu duyguları hissedecekleri faaliyetlerde bulunmaktadırlar (Ellis ve Knaus, 1977; Knaus, 2000). Bu bağlamda algilanan risk bu eyleme engel teşkil etmektedir.

\subsubsection{Genel Erteleme Eğilimi ve Online Satın Alma Davranışı Arasındaki İlişsiler}

Erteleme, pazarlama araştırmacıları tarafından satın alma gecikmesini açıklamak için de değerlendirilmiştir (Darpy, 2000). Darpy (2000), "planlanan bir satın almayı yavaşlatma veya geri tutma konusundaki kronik ve bilinçli eğilim" anlamına gelen "tüketici erteleme" sini incelemiştir. Tüketici boyutundan bakıldığında iki boyutla anlaşılmakta olup kararsızlık ve çatışmadan kaçınma olarak baz alınmaktadır.

\subsubsection{Online Erteleme Eğilimi ve Online Satın Alma Davranışı Arasındaki İlişskiler}

Online ertelemenin, modern ortamı internet olup kişilerin yer değiştirmeden, evde, işte, okulda hızlı bir şekilde eğlenceli ortama geçişi sağlamaktadır. Olumlu duygular yaratmanın bir yolu, tüketim davranışı özellikle de hedonik değeri olan ürünlerin satın alınması olmaktadır (Garge vd., 2007). Genel alan yazında tüketici odaklı Mzoughi vd. (2007) e-erteleme kavramını öngören bir araştırma yapmışlardır. Araştırma sonucuna göre online alışverişe karşı olumsuz tutum, online satın alma işleminin karmaşıklığı, fiyat algısı ve algılanan riskler online tüketici ertelemesini açıklamaktadır.

\subsubsection{Akış Deneyimi ve Online Satın Alma Davranışı Arasındaki İlişkiler}

Online satın alma davranışı, insan-bilgisayar etkileşimi bağlamında akış deneyimi tarafından en sık kullanılan kavramlardan biri olarak kendini göstermektedir (Mahnke vd., 2014). 
Akış kavramının çok boyutlu değerlendirmesini yapan araştırmalarda, akış deneyiminin çevrimiçi satın alma üzerinde güçlü bir olumlu etkiye sahip olmadığını ortaya koymuştur. Ayrıntılı olarak, çok boyutlu akış, akış deneyiminin çevrimiçi satın alma üzerinde olumlu (Hausman ve Siekpe, 2009), olumsuz (Shang vd., 2005) sonucuna varılmıştır.

\subsubsection{Algılanan Risk ve Online Satın Alma Davranışı Arasındaki İlişkiler}

Online platformlar tüketicilere birçok kolaylıklar sağlasa da online satın alma, tutum, niyet, davranış açısından riskler taşıdığı ve tüketicilerin bundan etkilendiği görülmektedir. Geleneksel satın alma (alışveriş) sürecinde riskler bulunmasına rağmen tüketiciler online alışveriş sürecini daha riskli bulmaktadırlar (Thakur ve Srivasta, 2014).

\section{ARAŞTIRMANIN AMACI VE YÖNTEMI}

$\mathrm{Bu}$ bölümde, araştırmanın amacı, örneklemi, veri toplama yöntemleri, araştırma modeli, hipotezler ve bulgulara ilişkin bilgilere yer verilmektedir.

\subsection{Araştırmanın Amacı}

$\mathrm{Bu}$ çalışmanın amacı, genel erteleme davranışı, akış deneyimi, online erteleme davranışı ve algılanan risk kavramlarının online satın alma davranışına etkilerini incelemektir. Genel erteleme, online erteleme davranışı ve akış deneyimi kavramları psikoloji disiplinine ait olup pazarlama alanında pazarlamacılara, pazardaki yeni hedef kitle oluşumuna, e-ticarette yeni tüketici yaklaşımına, rakiplerine karşı rekabet gücünü arttırma ve potansiyel tüketicilerin farkındalıklarına katkı sağlayacağı düşünülmektedir.

\subsection{Araştırmanın Örneklemi ve Veri Toplama Yöntemi}

Çalışmanın örneklemini kolayda örnekleme yöntemi ile seçilmiş, Sakarya, Ankara ve İstanbul illerinde yaşayan, 551 katılımcı oluşturmaktadır. Verilerin toplanması sürecinde anket yöntemi benimsenmiş olup ulaşılabilen kişilere "bırak-topla", farklı illerdeki kişilere ulaşmada "e-posta" yöntemi olarak iki yol izlenmiştir.

Araştırma bağlamında kullanılan örnek kütlenin demografik özelliklerine ilişkin bilgiler Tablo 1'de verilmektedir. Tablo incelendiğinde, katılımcıların \%62 oranında kadınlardan oluştuğu; \%64'ünün evli olduğu yaş olarak da yaklaşık \%43'ünün 34-49 ve \%19'u 18-25 yaş aralığında olduğu görülmektedir. Öğrenim düzeyleri açısından bakıldığında katılımcıların yaklaşık \%65'i ön lisans ve lisans, $\% 21$ 'i lise mezunudur. Aylık gelir dağılımlarına bakıldığında katılımcıların yaklaşık \%46'sı 2000-4000 TL, yaklaş1k \%26'sı 4000-6000 TL, \%13'ü 0-2000 TL,\%9'u ise 6000-8000 TL aralığındadır. Mesleki dağılımlara bakıldığında katılımcıların\%31,6'sı memur, \%14'ü işçi, \%6'sı öğrenci ve yaklaşık \%3'ü ev hanımı ve kalan \%37'si diğer(avukat, asker, aşçı, eczacı vb.) kategorisinde yer almaktadır.

Tablo 1:Katılımcıların Demografik Özellikleri

\begin{tabular}{|c|c|c|c|c|c|}
\hline Özellikler & 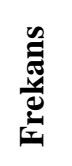 & 2 & 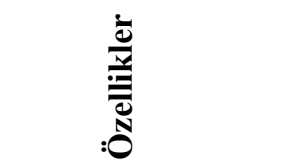 & 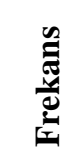 & $s^{e}$ \\
\hline Meslek & & & Yaș & & \\
\hline Öğrenci & 31 & 5,6 & $18-25$ & 105 & 19,1 \\
\hline Memur & 174 & 31,6 & $26-33$ & 127 & 23 \\
\hline Serbest Meslek & 47 & 8,5 & $34-41$ & 142 & 25,8 \\
\hline İşçi & 79 & 14,3 & $42-49$ & 91 & 16,5 \\
\hline Ev Hanımı & 16 & 2,9 & $50-57$ & 54 & 9,8 \\
\hline Diğer & 204 & 37 & 58 ve üstü & 32 & 5,8 \\
\hline Cinsiyet & & & Öğrenim Durumu & & \\
\hline Erkek & 341 & 62 & İlköğretim & 30 & 5,4 \\
\hline \multirow[t]{3}{*}{ Kadın } & 210 & 38 & Lise & 116 & 21,1 \\
\hline & & & Önlisans & 114 & 20,7 \\
\hline & & & Lisans & 248 & 45 \\
\hline Aylık Gelir & & & Lisansüstü & 43 & 7,8 \\
\hline $0-2000 \mathrm{TL}$ & 74 & 13,4 & & & \\
\hline $2001-4000 \mathrm{TL}$ & 254 & 46,1 & Medeni Durum & & \\
\hline $4001-6000 \mathrm{TL}$ & 141 & 25,6 & Evli & 351 & 64 \\
\hline
\end{tabular}




\begin{tabular}{|c|c|c|c|c|c|}
\hline $6001-8000$ & 50 & 9,1 & Bekar & 200 & 36 \\
\hline $8001-10.000 \mathrm{TL}$ & 18 & 3,3 & & & \\
\hline 10.000 TL ve üstü & 14 & 2,5 & & & \\
\hline \multicolumn{4}{|c|}{ TOPLAM } & 551 & 100 \\
\hline
\end{tabular}

\subsection{Araştırmanın Değişkenleri}

Tüm araştırma kapsamında, genel erteleme, akış deneyimi, online erteleme, algılanan risk değişkenlerini ölçmeye yönelik katılımcılardan yargılara, 5'li Likert Ölçeği kullanarak (1=Hiç Katılmıyorum, 2=Katılmiyorum, 3=Ne kat1liyorum Ne Katımıyorum, 4=Katılıyorum, 5=Tamamen Kat1liyorum) cevap verilmesi istenmiştir.

Genel Erteleme Ölçeği, Lay (1986) tarafindan geliştirilen genel erteleme ölçeği; tek boyutlu ve 20 ifadeden oluşmaktadır.

Algılanan risk ölçeği, Forsythe ve Shi (2003) tarafından geliştirilen ve uyarlanan algılanan risk ölçeği; "finansal risk", “ ürün riski” ve "zaman riski” olmak üzere üç boyuttan ve 12 ifadeden oluşmaktadır.

Online Erteleme Ölçeği, Thatcher vd. (2008) tarafindan geliştirilen ve uyarlanan online erteleme ölçeği tek boyuttan ve 7 ifadeden oluşan tek boyutlu bir yapı olarak tanımlanmıştı

Akış Deneyimi Ölçeği , konsantrasyon, alışveriş keyfi, tele bulunma ve zaman çarpıklığı boyutlarından oluşan; dört boyutlu bir yapı olarak tanımlanmıştır. Konsantrasyon boyutu Ghani (1991) ve Deshpande (1994)", "alışveriş keyfi boyutu Ghani (1991)", "tele bulunma boyutu(teleprensence). Kim ve Biocca (1997), zaman çarpıklığı boyutu(time distortion); Steuer(1992)" olarak dört tane alt boyuttan ve 17 ifadeden oluşmaktadır.

Online Satın Alma Davranışı Ölçeği, Bridges ve Florsheim (2008); Seock ve Bailey (2008) tarafından geliştirilen ve uyarlanan ölçekte olup tek boyuttan ve 5 ifadeden oluşmaktadır. Katılımcılardan, ilk soruda "Haftalık ortalama alışveriş sitelerini kaç kez ziyaret ediyorsunuz?" OS*1, $1=1 \mathrm{kez}, 2=2 \mathrm{kez}, 3=3 \mathrm{kez}$, $4=4 \mathrm{kez}, 5=5 \mathrm{kez}, 6 \mathrm{ve}$ üstü $=6 \mathrm{kez}$ ve üzeri sayılara eşit , İkinci soruda "Haftalık ortalama web sitesinde kaç saat kalıyorsunuz?" OS $* 2,1=1$ saat, $2=2$ saat, $3=3$ saat, $4=4$ saat, $5=5$ saat, 6 ve üstü $=6$ saat ve üzeri sayılara eşit, üçüncü soruda "Ortalama kaç ziyaretten sonra satın almaya karar veriyorsunuz? OS*3, $1=1$ ziyaretten sonra, $2=2$ ziyaretten sonra, $3=3$ ziyaretten sonra, $4=4$ ziyaretten sonra, $5=5$ ziyaretten sonra, 6 ve üstü $=6$ ziyaretten sonra ve üzeri sayılara eşit, "Kaç kere online satın alma (alışveriş) yapıyorsunuz?(AYLIK) OS*4, , $1=1$ kere, $2=2$ kere, $3=3$ kere, $4=4$ kere, $5=5$ kere , 6 ve üstü $=6$ kere ve üzeri sayılara eşit, "Son bir y1l içinde kaç kere online alışverişe katıldınız? OS*5, 1-5=1 ile 5 dahil ve arasındaki rakamlar kadar kere, 6-10=6 ile 10 sayıları dahil arasındaki sayılar kadar kere, 11-15=11 ile 15 sayıları dahil arasındaki sayılar kere, 16-20=16 ile 20 sayıları dahil arasındaki sayılar kadar kere, 21 ve üstü= 21 sayısı dahil üzeri sayılar kadar kereyi ifade ederek cevap verilmesi istenmiştir.

\subsection{Araştırmanın Modeli ve Hipotezleri}

Araştırmanın modeli, yapılan literatür taraması sonucunda, araştırmada kullanılan değişkenler temel alınarak Şekil 1'de gösterilmiştir.

\section{Şekil 1. Araştırma Modeli}

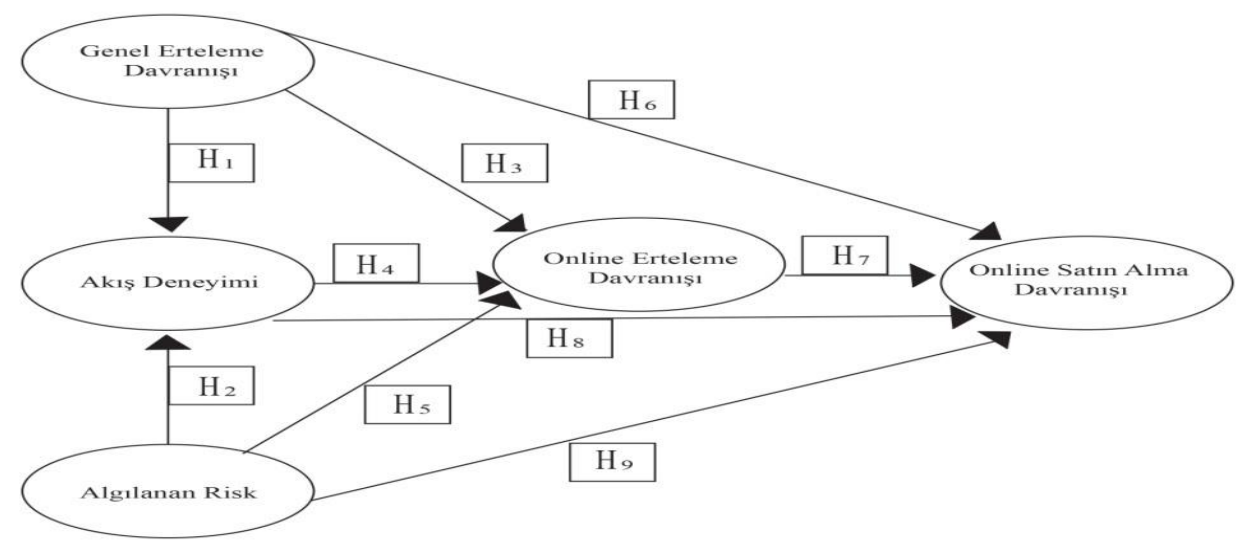




\subsubsection{Araştırmanın Hipotezleri}

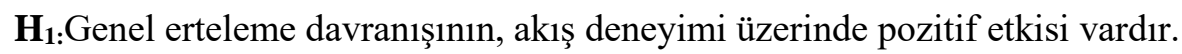

$\mathbf{H}_{2}$ : Algılanan riskin, akış deneyimi üzerinde negatif etkisi vardır.

$\mathbf{H}_{3}$ :Genel erteleme davranışının, online erteleme üzerinde pozitif etkisi vardır.

$\mathbf{H}_{4}$ :Akış deneyiminin, online erteleme davranışı üzerinde pozitif etkisi vardır.

$\mathbf{H}_{5}$ :Algilanan riskin, online erteleme davranışı üzerinde negatif etkisi vardır.

H6: Genel erteleme davranışının, online satın alma davranışı üzerinde negatif etkisi vardır.

$\mathbf{H}_{7}$ :Online erteleme davranışının, online satın alma davranışı üzerinde negatif etkiye sahiptir.

$\mathbf{H}_{8}$ :Akış deneyimi, online satın alma davranışı üzerinde pozitif etkisi vardır.

H9:Algılanan riskin, online satın alma davranışı üzerinde negatif etkisi vardır.

\section{BULGULAR}

\subsection{Araştırmada Kullanılan Ölçeklere İlişkin Geçerlik ve Güvenirlik Analizleri}

Tablo 2: Ölçüm Modeli Sonuçları

\begin{tabular}{|c|c|c|c|c|c|}
\hline Değişken & İfade & $\begin{array}{l}\text { Faktör } \\
\text { Yükü }\end{array}$ & $\begin{array}{c}\text { Cronbach } \\
\text { Alfa }\end{array}$ & $\mathbf{C R}$ & AVE \\
\hline \multirow{3}{*}{$\begin{array}{c}\text { DÜZENLİ } \\
\text { YAŞAYANLAR }\end{array}$} & DGE3 & 0,752 & \multirow{3}{*}{0,555} & \multirow{3}{*}{0,771} & \multirow{3}{*}{0,529} \\
\hline & DGE4 & 0,761 & & & \\
\hline & DGE6 & 0,665 & & & \\
\hline \multirow{3}{*}{ ERTELEYENLER } & GE1 & 0,633 & \multirow{3}{*}{0,624} & \multirow{3}{*}{0,787} & \multirow{3}{*}{0,555} \\
\hline & GE2 & 0,762 & & & \\
\hline & GE11 & 0,827 & & & \\
\hline \multirow{2}{*}{$\begin{array}{c}\text { SON ANA } \\
\text { BIRAKANLAR }\end{array}$} & SDE16 & 0,790 & \multirow{2}{*}{0,617} & \multirow{2}{*}{0,835} & \multirow{2}{*}{0,718} \\
\hline & SDE17 & 0,901 & & & \\
\hline \multirow{5}{*}{ TEZ CANLILIK } & TGE13 & 0,600 & \multirow{5}{*}{0,798} & \multirow{5}{*}{0,860} & \multirow{5}{*}{0,557} \\
\hline & TGE14 & 0,874 & & & \\
\hline & TGE15 & 0,843 & & & \\
\hline & TGE18 & 0,754 & & & \\
\hline & TGE20 & 0,617 & & & \\
\hline \multirow{4}{*}{ FINANSAL RİSK } & FR3 & 0,600 & \multirow{4}{*}{0,746} & \multirow{4}{*}{0,837} & \multirow{4}{*}{0,566} \\
\hline & FR4 & 0,768 & & & \\
\hline & FR5 & 0,797 & & & \\
\hline & UR6 & 0,823 & & & \\
\hline \multirow{2}{*}{ ÜRÜN RİSKİ } & UR8 & 0,887 & \multirow{2}{*}{0,742} & \multirow{2}{*}{0,886} & \multirow{2}{*}{0,795} \\
\hline & UR9 & 0,896 & & & \\
\hline \multirow{4}{*}{ ZAMAN RİSKİ } & FR1 & 0,762 & \multirow{4}{*}{0,799} & \multirow{4}{*}{0,865} & \multirow{4}{*}{0,615} \\
\hline & ZR10 & 0,764 & & & \\
\hline & ZR11 & 0,834 & & & \\
\hline & ZR12 & 0,775 & & & \\
\hline \multirow{4}{*}{$\begin{array}{c}\text { KONSANTRASYO } \\
\mathrm{N}\end{array}$} & KON1 & 0,928 & \multirow{4}{*}{0,919} & \multirow{4}{*}{0,943} & \multirow{4}{*}{0,807} \\
\hline & KON2 & 0,945 & & & \\
\hline & KON3 & 0,917 & & & \\
\hline & KON4 & 0,796 & & & \\
\hline
\end{tabular}

Yapıların Cronbach Alfa katsayılarının 0,555 ile 0,923; CR katsayılarının da 0,860 ile 0,943 arasında hesaplanması nedeniyle iç tutarlılık güvenirliğinin sağlandığg ifade edilebilir.

Tablodaki değerler incelendiğinde, faktör yüklerinin 0,600 ile 0,945 arasında gerçekleştiği görülmektedir. Hair vd. (2014) faktör yüklerinin 0,40'nın altında olan ifadelerin ölçüm modelinden çıkarılmasını gerektiğini; faktör yükleri 0,40 ile 0,70 arasında olan ifadelerin ise AVE ya da CR değerlerinin eşik değerin altında olması durumunda modelden çıkarılmasını önermektedir.

CR ve AVE değerleri eşik değerin altında olması nedeniyle; erteleme eğilimi boyutunun GE7 "ufak tefek işler oturulup yapılmadığında günlerce zamanımı alır"; son ana bırakma boyutunun SAB5 "Bir evrağı postaya vermeden önce masanın üzerinde birkaç gün beklediği olur" ile SAB19 "Sürekli olarak yarın yapacağımı 
söylerim" ile online erteleme değişkeninin OE1 "İnternette olduğum zaman sorumluluklarım hakkında düşünmem” ifadeleri ölçüm modelinden çıkartılmıştır.

Faktör yüklerinin 0,600 ile 0,945 arasında; AVE değerlerinin de 0,529 ile 0,807 arasında gerçekleşmesi nedeniyle birleşme geçerliğiyle ilgili gerekli koşulların sağlandığı anlaşılmıştır.

Ayrışma geçerliğinin tespitinde, Fornell ve Larcker (1981) tarafindan önerilen kriter ile Henseler vd. (2015) tarafından önerilen HTMT kriterleri kullanılmıştır. Fornell ve Larcker (1981) kriterine göre, araştırmada yer alan yapıların açıklanan ortalama varyans (AVE) değerlerinin karekökü, araştırmada yer alan yapılar arasındaki korelâsyonlardan yüksek olmalıdır. Tablo 3 Fornell ve Larcker (1981) kriterine göre yapılan analiz sonuçları yer almaktadır (Henseler vd., 2015).

Tablo 4'de HTMT katsayıları gösterilmiştir (Henseler vd., 2015). Tablodaki değerler incelendiğinde HTMT değerlerinin eşik değerin altında olduğu görülmektedir.

Tablo 3 ve Tablo 4'de ki bulgulara dayanarak ayrışma geçerliliğinin sağlandığ belirtilebilir.

Tablo3:Ayrışma Geçerliği Sonuçları (Fornell ve Larckell Kriteri)

\begin{tabular}{|c|c|c|c|c|c|c|c|c|c|c|c|c|}
\hline & DEY & GE & KEY & KON & OE & OS & FR & SDE & $\begin{array}{c}\text { TE } \\
\text { LE }\end{array}$ & TGE & ZR & UR \\
\hline DEY & $\mathbf{0 , 7 2 7}$ & & & & & & & & & & & \\
\hline GE & 0,185 & $\mathbf{0 , 7 4 5}$ & & & & & & & & & & \\
\hline KEY & $-0,081$ & 0,173 & $\mathbf{0 , 8 2 4}$ & & & & & & & & & \\
\hline KON & $-0,276$ & $-0,111$ & 0,150 & $\mathbf{0 , 8 9 9}$ & & & & & & & & \\
\hline OE & 0,174 & 0,319 & 0,255 & $-0,101$ & $\mathbf{0 , 7 3 8}$ & & & & & & & \\
\hline OS & $-0,063$ & 0,105 & 0,250 & $-0,097$ & 0,150 & $\mathbf{0 , 8 1 1}$ & & & & & & \\
\hline FR & $-0,014$ & 0,027 & 0,023 & 0,127 & 0,072 & $-0,204$ & $\mathbf{0 , 7 5 2}$ & & & & & \\
\hline SDE & 0,096 & 0,342 & 0,036 & $-0,042$ & 0,230 & $-0,058$ & 0,092 & $\mathbf{0 , 8 4 7}$ & & & & \\
\hline TE & 0,177 & 0,227 & 0,296 & $-0,109$ & 0,548 & 0,140 & 0,050 & 0,214 & $\mathbf{0 , 7 8 7}$ & & & \\
LE & & & & & & & & & \\
\hline TGE & 0,456 & 0,242 & $-0,108$ & $-0,523$ & 0,141 & 0,060 & $-0,120$ & 0,103 & 0,154 & $\mathbf{0 , 7 4 6}$ & & \\
\hline ZR & $-0,019$ & 0,009 & $-0,080$ & 0,181 & 0,061 & $-0,402$ & 0,431 & 0,145 & 0,099 & $-0,183$ & $\mathbf{0 , 7 8 4}$ & \\
\hline UR & $-0,097$ & $-0,003$ & 0,087 & 0,103 & 0,050 & $-0,181$ & 0,369 & $-0,017$ & $-0,014$ & $-0,225$ & 0,280 & $\mathbf{0 , 8 9 2}$ \\
\hline
\end{tabular}

Tablo 4:Ayrışma Geçerliği Sonuçları (HTMT Kriteri)

\begin{tabular}{|l|c|c|c|c|c|c|c|c|c|c|c|c|}
\hline & DEY & GE & KEY & KON & OE & OS & FR & SDE & $\begin{array}{c}\text { TE } \\
\text { LE }\end{array}$ & TGE & ZR & UR \\
\hline DEY & & & & & & & & & & & & \\
\hline GE & 0,300 & & & & & & & & & & & \\
\hline KEY & 0,132 & 0,223 & & & & & & & & & & \\
\hline KON & 0,381 & 0,160 & 0,167 & & & & & & & & & \\
\hline OE & 0,250 & 0,421 & 0,313 & 0,122 & & & & & & & & \\
\hline OS & 0,115 & 0,149 & 0,294 & 0,116 & 0,179 & & & & & & & \\
\hline FR & 0,118 & 0,072 & 0,086 & 0,142 & 0,106 & 0,244 & & & & & & \\
\hline SDE & 0,156 & 0,563 & 0,081 & 0,066 & 0,320 & 0,086 & 0,134 & & & & & \\
\hline TE & 0,243 & 0,262 & 0,342 & 0,122 & 0,613 & 0,158 & 0,095 & 0,271 & & & & \\
LE & 0,696 & 0,364 & 0,134 & 0,585 & 0,176 & 0,095 & 0,177 & 0,164 & 0,180 & & & \\
\hline TGE & 0,610 & & \\
\hline ZR & 0,110 & 0,110 & 0,093 & 0,191 & 0,082 & 0,460 & 0,535 & 0,191 & 0,126 & 0,209 & & \\
\hline UR & 0,161 & 0,092 & 0,122 & 0,123 & 0,098 & 0,232 & 0,502 & 0,132 & 0,081 & 0,299 & 0,360 & \\
\hline
\end{tabular}




\subsection{Araştırma Modelinin Analizi}

Şekil 2:Yapısal Eşitlik Modeli

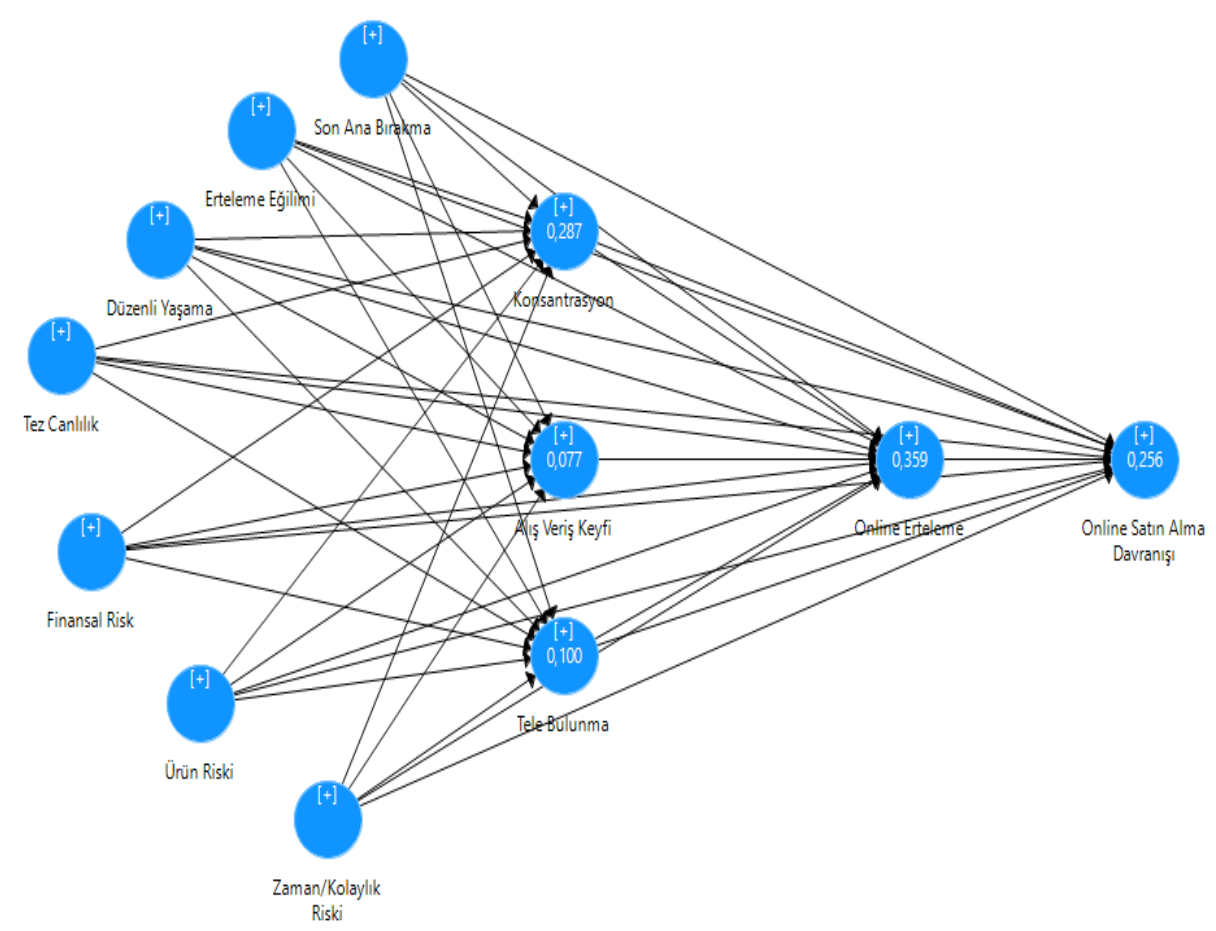

Hipotezlerin testi için oluşturulan yapısal eşitlik modeli Şekil 2'de gösterilmiştir. Verilerin analizi için SmartPLS 3.2.9 programı kullanılmıştır (Ringle, Wende ve Becker, 2015). Doğrusallık ve $\mathrm{R}^{2}$ için PLS algoritması; tahmin gücü $\left(\mathrm{Q}^{2}\right)$ için de blinfolding analizi çalıştırılmıştır. Türev örnekleme ile örneklemden 5000 alt örneklem alınarak $t$ değerleri hesaplanmıştır. Tablo 5'de; VIF, $\mathrm{R}^{2}$ ve $\mathrm{Q}^{2}$ katsayıları gösterilmiştir.

Hair vd. (2014) değişkenler arasında doğrusallıkla ilgili bir problem olmaması için VIF (Variance Inflation Factor) katsayılarının eşik değer olan 5'in altında gerçekleşmiş olması gerekmektedir. Tablo 5'deki VIF katsayıları 5'in altında olduğu için değişkenler arasında doğrusallık problemi olmadığı gözlemlenmiştir.

$\mathrm{R}^{2}$ değerleri incelendiğinde alışveriş keyfinin \%7,7, konsantrasyonun \%28,7, online ertelemenin \%35,9, tele bulunmanın \%10 ve online satın almanın \%25,6 oranında açıklandığı tespit edilmiştir.

Yapısal modelde açıklanmaya çalışılan endojen değişkenlere yönelik modelin tahmin gücü blindfolding analizi ile hesaplanmaktadır. Analiz sonucunda tahmin gücü katsayısının $\left(\mathrm{Q}^{2}\right)$ sıfırdan büyük olması modelin endojen değişkenleri tahmin gücüne sahip olduğunu göstermektedir (Hair vd., 2014). Tablo 5 'de tahmin gücü katsayılarının sıfırdan büyük olduğu görülmektedir. Bu nedenle oluşturulan yapısal modelin tahmin gücüne sahip olduğu ifade edilebilir.

Tablo 5: Araştırma Modeli Katsayıları

\begin{tabular}{|c|c|c|c|c|}
\hline Değişk & nler & VIF & $\mathbf{R}^{2}$ & $\mathbf{Q}^{2}$ \\
\hline Düzenli Yaşama & \multirow{11}{*}{$\begin{array}{l}\text { Online Satın } \\
\text { Alma Dav. }\end{array}$} & 1,308 & \multirow{11}{*}{0,256} & \multirow{11}{*}{0,159} \\
\hline Erteleme Eğilimi & & 1,300 & & \\
\hline Son Ana Bırakma & & 1,196 & & \\
\hline Tez Canlılık & & 1,750 & & \\
\hline Finansal Risk & & 1,348 & & \\
\hline Ürün Riski & & 1,247 & & \\
\hline Zaman Riski & & 1,369 & & \\
\hline Konsantrasyon & & 1,439 & & \\
\hline Alışveriş Keyfi & & 1,246 & & \\
\hline Tele Bulunma & & 1,571 & & \\
\hline Online Erteleme & & 1,560 & & \\
\hline Düzenli Yaşama & Online Erteleme & 1,303 & 0,359 & 0,187 \\
\hline
\end{tabular}




\begin{tabular}{|c|c|c|c|c|}
\hline Erteleme Eğilimi & & 1,259 & & \\
\hline Son Ana Birakma & & 1,190 & & \\
\hline Tez Canlılık & & 1,750 & & \\
\hline Finansal Risk & & 1,347 & & \\
\hline Ürün Riski & & 1,243 & & \\
\hline Zaman Riski & & 1,369 & & \\
\hline Konsantrasyon & & 1,437 & & \\
\hline Alışveriş Keyfi & & 1,232 & & \\
\hline Tele Bulunma & & 1,248 & & \\
\hline Düzenli Yaşama & \multirow{7}{*}{ Konsantrasyon } & 1,279 & \multirow{7}{*}{0,287} & \multirow{7}{*}{0,223} \\
\hline Erteleme Eğilimi & & 1,201 & & \\
\hline Son Ana Birakma & & 1,343 & & \\
\hline Tez Canılık & & 1,399 & & \\
\hline Finansal Risk & & 1,343 & & \\
\hline Ürün Riski & & 1,228 & & \\
\hline Zaman Riski & & 1,304 & & \\
\hline Düzenli Yaşama & \multirow{7}{*}{ Alışveriş Keyfi } & 1,279 & \multirow{7}{*}{0,077} & \multirow{7}{*}{0,043} \\
\hline Erteleme Eğilimi & & 1,201 & & \\
\hline Son Ana Birakma & & 1,168 & & \\
\hline Tez Canlılık & & 1,399 & & \\
\hline Finansal Risk & & 1,343 & & \\
\hline Ürün Riski & & 1,228 & & \\
\hline Zaman Riski & & 1,304 & & \\
\hline Düzenli Yaşama & \multirow{7}{*}{ Tele Bulunma } & 1,279 & \multirow{7}{*}{0,100} & \multirow{7}{*}{0,059} \\
\hline Erteleme Eğilimi & & 1,201 & & \\
\hline Son Ana Birakma & & 1,168 & & \\
\hline Tez Canlılık & & 1,399 & & \\
\hline Finansal Risk & & 1,343 & & \\
\hline Ürün Riski & & 1,228 & & \\
\hline Zaman Riski & & 1,304 & & \\
\hline
\end{tabular}

Tablo 6: Araştırma Modeli Doğrudan Etki Katsayıları

\begin{tabular}{|c|c|c|c|c|c|c|c|}
\hline \multicolumn{2}{|c|}{ Değişkenler } & $\begin{array}{c}\text { Standar } \\
\text { dize } \beta\end{array}$ & S.S. & $\begin{array}{c}t- \\
\text { değeri }\end{array}$ & $\begin{array}{c}\text { p- } \\
\text { değeri }\end{array}$ & $\begin{array}{c}\text { Hipotez } \\
\text { Kodu }\end{array}$ & $\begin{array}{c}\text { Kabul/ } \\
\text { red }\end{array}$ \\
\hline Tez Canlılık & \multirow{4}{*}{$\begin{array}{l}\text { KONSANTRASYON } \\
\text { (Akış Deneyimi) }\end{array}$} & $-0,491$ & 0,040 & 12,162 & 0,000 & $\mathrm{H}_{1 \mathrm{a}}$ & Kabul \\
\hline Düzenli Yaşama & & $-0,058$ & 0,040 & 1,461 & 0,144 & $\mathrm{H}_{1 \mathrm{~b}}$ & Red \\
\hline Erteleme Eğilimi & & 0,020 & 0,040 & 0,500 & 0,617 & $\mathrm{H}_{1 \mathrm{c}}$ & Red \\
\hline Son Ana Bırakma & & $-0,010$ & 0,043 & 0,242 & 0,809 & $\mathrm{H}_{1 \mathrm{~d}}$ & Red \\
\hline Tez Canlılık & \multirow{4}{*}{$\begin{array}{l}\text { ALIŞ VERİŞ KEYFİ } \\
\text { (Akış Deneyimi) }\end{array}$} & $-0,143$ & 0,055 & 2,580 & 0,010 & $\mathrm{H}_{1 \mathrm{e}}$ & Kabul \\
\hline Düzenli Yaşama & & $-0,051$ & 0,055 & 0,937 & 0,349 & $\mathrm{H}_{1 \mathrm{f}}$ & Red \\
\hline Erteleme Eğilimi & & 0,218 & 0,048 & 4,518 & 0,000 & $\mathrm{H}_{1 \mathrm{~g}}$ & Kabul \\
\hline Son Ana Birakma & & 0,000 & 0,049 & 0,010 & 0,992 & $\mathrm{H}_{1 \mathrm{~h}}$ & Red \\
\hline Tez Canlılık & \multirow{4}{*}{$\begin{array}{c}\text { Tele Bulunma (Akış } \\
\text { Deneyimi) }\end{array}$} & 0,071 & 0,053 & 1,355 & 0,175 & $\mathrm{H}_{1 \mathrm{i}}$ & Red \\
\hline Düzenli Yaşama & & 0,105 & 0,054 & 1,935 & 0,053 & $\mathrm{H}_{1 \mathrm{j}}$ & Kabul \\
\hline Erteleme Eğilimi & & 0,144 & 0,047 & 3,075 & 0,002 & $\mathrm{H}_{1 \mathrm{k}}$ & Kabul \\
\hline Son Ana Bırakma & & 0,133 & 0,049 & 2,706 & 0,007 & $\mathrm{H}_{11}$ & Kabul \\
\hline Finansal Risk & \multirow{3}{*}{$\begin{array}{l}\text { KONSANTRASYON } \\
\text { (Akış Deneyimi) }\end{array}$} & 0,052 & 0,049 & 1,057 & 0,290 & $\mathrm{H}_{2 \mathrm{a}}$ & Red \\
\hline Ürün Riski & & $-0,056$ & 0,043 & 1,320 & 0,187 & $\mathrm{H}_{2 \mathrm{~b}}$ & Red \\
\hline Zaman Riski & & 0,084 & 0,045 & 1,893 & 0,058 & $\mathrm{H}_{2 \mathrm{c}}$ & Red \\
\hline
\end{tabular}




\begin{tabular}{|c|c|c|c|c|c|c|c|}
\hline Finansal Risk & \multirow{3}{*}{$\begin{array}{l}\text { ALIŞ VERIŞ KEYFi } \\
\text { (Akış Deneyimi) }\end{array}$} & 0,032 & 0,062 & 0,523 & 0,601 & $\mathrm{H}_{2 \mathrm{~d}}$ & Red \\
\hline Ürün Riski & & 0,079 & 0,055 & 1,449 & 0,147 & $\mathrm{H}_{2 \mathrm{e}}$ & Red \\
\hline Zaman Riski & & $-0,146$ & 0,062 & 2,376 & 0,018 & $\mathrm{H}_{2 \mathrm{f}}$ & Kabul \\
\hline Finansal Risk & \multirow{3}{*}{$\begin{array}{l}\text { Tele Bulunma } \\
\text { (Akış Deneyimi) }\end{array}$} & 0,009 & 0,055 & 0,166 & 0,868 & $\mathrm{H}_{2 \mathrm{~g}}$ & Red \\
\hline Ürün Riski & & $-0,014$ & 0,050 & 0,283 & 0,777 & $\mathrm{H}_{2 \mathrm{~h}}$ & Red \\
\hline Zaman Riski & & 0,093 & 0,050 & 1,849 & 0,064 & $\mathrm{H}_{2 \mathrm{i}}$ & Red \\
\hline Tez Canlılık & \multirow{4}{*}{ Online Erteleme } & 0,006 & 0,049 & 0,119 & 0,905 & $\mathrm{H}_{3 \mathrm{a}}$ & Red \\
\hline Düzenli Yaşama & & 0,059 & 0,044 & 1,344 & 0,179 & $\mathrm{H}_{3 \mathrm{~b}}$ & Red \\
\hline Erteleme Ĕgilimi & & 0,161 & 0,045 & 3,584 & 0,000 & $\mathrm{H}_{3 \mathrm{c}}$ & Kabul \\
\hline Son Ana Bırakma & & 0,066 & 0,041 & 1,611 & 0,107 & $\mathrm{H}_{3 \mathrm{~d}}$ & Red \\
\hline Konsantrasyon & \multirow{3}{*}{ Online Erteleme } & $-0,034$ & 0,044 & 0,759 & 0,448 & $\mathrm{H}_{4 \mathrm{a}}$ & Red \\
\hline Alışveriş Keyfi & & 0,095 & 0,048 & 1,994 & 0,046 & $\mathrm{H}_{4 \mathrm{~b}}$ & Kabul \\
\hline Tele Bulunma & & 0,455 & 0,043 & 10,659 & 0,000 & $\mathrm{H}_{4 \mathrm{c}}$ & Kabul \\
\hline Finansal Risk & \multirow{3}{*}{ Online Erteleme } & 0,026 & 0,043 & 0,597 & 0,551 & $\mathrm{H}_{5 \mathrm{a}}$ & Red \\
\hline Ürün Riski & & 0,053 & 0,043 & 1,232 & 0,218 & $\mathrm{H}_{5 \mathrm{~b}}$ & Red \\
\hline Zaman Riski & & $-0,005$ & 0,042 & 0,129 & 0,897 & $\mathrm{H}_{5 \mathrm{c}}$ & Red \\
\hline Tez Canlılık & \multirow{4}{*}{$\begin{array}{c}\text { Online Satın Alma } \\
\text { Davranışı }\end{array}$} & $-0,039$ & 0,050 & 0,769 & 0,442 & $\mathrm{H}_{6 \mathrm{a}}$ & Red \\
\hline Düzenli Yaşama & & $-0,108$ & 0,045 & 2,412 & 0,016 & $\mathrm{H}_{6 \mathrm{~b}}$ & Kabul \\
\hline Erteleme Eğilimi & & 0,073 & 0,045 & 1,636 & 0,102 & $\mathrm{H}_{6 \mathrm{c}}$ & Red \\
\hline Son Ana Bırakma & & $-0,067$ & 0,042 & 1,599 & 0,110 & $\mathrm{H}_{6 \mathrm{~d}}$ & Red \\
\hline Online Erteleme & $\begin{array}{c}\text { Online Satın Alma } \\
\text { Davranışı }\end{array}$ & 0,097 & 0,052 & 1,848 & 0,065 & $\mathrm{H}_{7}$ & Red \\
\hline Konsantrasyon & \multirow{3}{*}{$\begin{array}{c}\text { Online Satın Alma } \\
\text { Davranışı }\end{array}$} & $-0,070$ & 0,045 & 1,563 & 0,118 & $\mathrm{H}_{8 \mathrm{a}}$ & Red \\
\hline Alışveriş Keyfi & & 0,169 & 0,041 & 4,124 & 0,000 & $\mathrm{H}_{8 \mathrm{~b}}$ & Kabul \\
\hline Tele Bulunma & & 0,084 & 0,053 & 1,583 & 0,113 & $\mathrm{H}_{8 \mathrm{c}}$ & Red \\
\hline Finansal Risk & \multirow{3}{*}{$\begin{array}{c}\text { Online Satın Alma } \\
\text { Davranışı }\end{array}$} & $-0,022$ & 0,045 & 0,482 & 0,630 & $\mathrm{H}_{9 \mathrm{a}}$ & Red \\
\hline Ürün riski & & $-0,107$ & 0,045 & 2,395 & 0,017 & $\mathrm{H}_{9 \mathrm{~b}}$ & Kabul \\
\hline Zaman Riski & & $-0,351$ & 0,039 & 9,083 & 0,000 & $\mathrm{H}_{9 \mathrm{c}}$ & Kabul \\
\hline
\end{tabular}

\section{SONUÇ VE TARTIŞMA}

Bu çalışmanın amacı, genel erteleme eğilimi, algılanan risk, akış deneyimi ve online erteleme eğilimi kavramlarının online satın alma davranışı üzerindeki etkisinin ortaya çıkarılması olarak belirlenmiştir. Farklı disiplinleri entegre ederek oluşturulan bu çalışma; pazarlamacılara, pazardaki yeni hedef kitle (erteleme eğilimli kişiler) oluşumuna, e-ticarette yeni tüketici yaklaşımına, işletmelerin rakiplerine karşı gücünün yükselmesine ve potansiyel tüketicilerin farkındalıklarına katkı sağlayacaktır.

Araştırmanın amacı doğrultusunda genel literatür taraması yapılarak model kurgulanmış olup yapısal eşitlik modellemesi ile test edilmiştir. Elde edilen sonuçlara göre tek boyutlu baz alınan genel erteleme ölçeği araştırmada gerek örneklem gerek kültürel farklılıklar sebebiyle dört boyutlu olarak ortaya çıkmıştır. Yapılan doğrulayıcı faktör analizine göre her boyut isimlendirilmiş̧ir. Bu boyutlar tez canlılık, düzenli yaşama, erteleme eğilimi ve son ana bırakmadır. Berk vd. (2021) yaptıkları çalışmada tek boyutlu olan genel erteleme eğilimi dört boyutlu olarak ortaya konmuştur.

Çalışma kapsamından elde edilen bulgular, erteleme eğilimli kişilerin online platformda satın alma davranışına negatif etki etmemesi dikkat çekmektedir. Bu durum erteleme eğilimli kişilerin sıkıcı durumlar konusunda ertelemeye yatkın olduklarını, alışveriş, eğlence vb. durumlarda etki etmediğini göstermektedir. Çalışmaya göre ortaya çıkan erteleme kavramındaki boyutlar ele alındığında sadece düzenli yaşayanlar boyutunda hipotez kabul görmüştür. Diğer boyutlar olan tez canlılık, son ana birakma ve erteleme eğilimi hipotezleri kabul görmemiştir. Bu bağlamda çalışmada baz alınan genel erteleme ve online erteleme kavramları yeni hedef kitlenin parçaları olup pazarlama alanında önem kazanacağı ve öncü bir çalışma olacağı düşünülmektedir. Geleneksel satın alma davranışı için gerekli olan hareket değişikliği yeni tüketici grubu olan erteleme eğilimli kişiler için gerek kalmamıştır. Bu grup teknolojinin sağladığı kolaylıklar sayesinde her an, her yerde sadece bir tuşla satıcıların hedefine girmişlerdir. Araştırmada kullanılan genel erteleme eğilimli kişilerin online erteleme sürecine geçiş sağladığı alış veriş keyfi 
ve ortama kendini kaptırma(tele-bulunma) durumu saptanmıştır. Bu durum literatürde bulunan araştırmalarla uyumlu durumdadır. Kişilerin online erteleme durumundayken finansal, ürün, zaman/kolaylık risklerinin negatif etki etmediği söylenebilmektedir. Ayrıca algılanan riskin finansal risk boyutunun, online satın alma davranışında negatif etkisinin olmadığı görülmüştür. Örneklem bazında ülkemiz açısından bakıldığından online satın alma davranışının olmamasının en büyük sebeplerinden biri olan finansal riskin negatif etki etmemesi sevindirici bir durumdur. Online ertelemeye, çalışmada değerlendirmeye alınan risklerin negatif etki etmemesi geleneksel platformdan online sürece geçişin sağlanmakta olduğuna dair yorumlar yapılabilmesine katkılı olmaktadır. Çalışma, tüm dünya da yaşanan pandemi sürecinden önce yapılmıştır. Olağanüstü durumun yaşattığı olumsuzluklar nedeniyle online alanda kişisel (önyargı, alışkanlık...vb.) yaklaşımlar değişmek durumunda kalmıştır. Çalışma pandemi sürecinden sonra yapılsaydı sonuçların farklılık göstereceği öngörülmektedir. Çalışmadan elde edilen bulguların sonucunda işletmeciler ve pazarlamacılar için erteleme eğilimli kişilerin yeni bir hedef kitle olduğu ve bu hedef kitleye yönelik pazarlama stratejilerini oluşturmaları için olumlu bir durumu yansıtmaktadır.

İşletmeciler ve pazarlamacılar için erteleme eğilimli kişileri saptamak, onlara özel kişileştirilmiş kapmayanların oluşturulması (son saat-dakika, rekabetçi fiyatlar ve ürün hakkında tam bilgi), sistem veri analizinin takibinin yapılması, sitede kaç saat kaldığı, acil ihtiyaçlarının belirlenmesi, tıklama akışının takibi, sepette bekletme durumlarının saptanması satışlarının artmasına destek sağlayacaktır.

Araştırmaya genel erteleme eğilimli kişiler tarafından bakıldığında online ertelemeye yatkın olduklarından işletmecilere ve pazarlamacılara karşı savunmasız duruma düşmelerine sebep olabilir. Kamu bilincinin arttırılması adına bu durumu açıklamada da fayda bulunmaktadır. 


\section{KAYNAKLAR}

Berk, Ö., Altunışık, R., Eskiler, E. ve Sarıkaya, N. (2021). Lay (1986)'nın Genel Erteleme Ölçeğinin Güvenilirlik ve Geçerlilik araştırması. Gümüşhane Üniversitesi Sosyal Bilimler Enstitüsü Elektronik Dergisi, 12(2), 614-626.

Bridges,E.ve Florsheim,R. (2008). Hedonic and Utilitarian Shopping Goals: The Online Experience. Journal of Business Research, 61(4), 309-314.

Chen, H. (2006). Flow on The Net-Detecting Web Users Positive Affects and Their Flow States. Computers in Human Behavior, 22,221 -233.

Cho, J. (2004). Likelihood to Abort an Online Transaction: Influences from Cognitive Evaluations, Attitudes, and Behavioral Variables. Information and Management, Vol. 41 No.7, pp. 827-38.

Chu, A. H. C. ve Choi,J. N. (2005). Rethinking Procrastination: Positive Effects of Active Procrastination Behavior on Attitudes and Performance. The Journal of Social Psychology, 145, 245-264.

Costa, R. C. ve Lucian, R. (2014). Structural Equations Modeling, Perceived Risk and Flow State on E-Commerce. iBusiness, 6, 38-43.

Cox,D.F. ve Rich,S. (1964). Perceived Risk and Consumer Decision Making: The Case of Telephone Shopping. Journal of Marketing Research, 1(4), 32-39.

Csikszentmihalyi, M. (1975). Beyond Boredom and Anxiety (1st Ed.). San Francisco: Jossey-Bass.

Csikszentmihalyi, M. (1990). Flow: The Psychology of Optimal Experience. New York: Harper and Row.

Cunnigham, S.M. (1967). The Major Dimensions of Perceived Risk. Risk Taking and Information Handling in Consumer Behavior (Editör Cox, D.F.). Harvard University Press, Boston: 82-108.

Darpy, D. (2000). Consumer Procrastination and Purchase Delay. 29th Annual Conference EMAC. Rotterdam, NL.

Ellis, A. ve Knaus, W.J. (1977). Overcoming Procrastination. New York: Signet Books.

Fornell,C.ve Larcker, D. F. (1981). Structural Equation Models with Unobservable Variables and Measurement Error: Algebra and Statistics. Journal of Marketing Research, 382-8.

Forsythe, S.M. ve Shi, B. (2003). Consumer Patronage and Risk Perceptions in Internet Shopping. Journal of Business Research, 56(11), 867-875.

Forsythe, S., Liu, C., Shannon, D. ve Gardner, L.C. (2006). Development of a Scale to Measure The Perceived Benefits and Risks Of Online Shopping. Journal of Interactive Marketing, Vol. 20, No.2, pp.55-75.

Garg, N., Wansink, B. ve Inman, J. J. (2007). The Influence of Incidental Affect On Consumers Food Intake. Journal of Marketing, 71(1), 194-206.

Garge S.C., Wetzel M. D. ve Ogunnaike B. A. ( 2007). An Inference Based Scheme for Controlling Product End-use Properties of Reactive Extrusion Processes. In preparation.

Ghani, J.A. (1991). Flow in Human-Computer Interactions: Test of a Model, In J. Carey (ed.) Human Factors in Management Information systems: An Organizational Perspective. Norwood, NJ: Ablex.

Hair, J.F., Tomas, G., Hult, M., Ringle, C.M., ve Sarstedt, M. (2014). A Primer on Partial Least Square Structural Equations Modeling (PLS-SEM). Los Angeles: Sage.

Hausman, A.V. ve Siekpe, J.S. (2009). The Effect of Web Interface Features on Consumer Online Purchase Intentions. Journal Business Research, pp. 5-13.

Hen, M. ve Goroshit, M. (2018). The Effects of Decisional and Academic Procrastination on Students Feelings toward Academic Procrastination. Current Psychology, 1-8.

Henseler, J., Ringle, C.M. ve Sarstedt, M. (2015). A New Criterion for Assessing Discriminant Validity in VarienceBased Structural Equation Modelling. Journal of the Academy of Marketing Science, 43, 115-135.

Horton Raymond, L. (1984). Buyer Behavior: A Decision Making Approach. New York: Charles Merrill.

https:// dictionary.apa.org/, 7.11.2018.

https:// dictionary.apa.org / time- distortion, 08.09.2019.

Huang, L., Hsieh, Y. ve Wu, Y. J. (2014). Gratifications and Social Network Service Usage: The Mediating Role of Online Experience. Information and Management, 51(6), 774-782.

Kim, T. ve Biocca, F. (1997). Telepresence Via Television: Two Dimensions of Telepresence may have Different Connections to Memory and Persuasion. Journal of Computer-Mediated Communication, 3(2), n.p.

Kim, K.R. ve Seo, E. H. (2015). The Relationship between Procrastination and Academic Performance: A Meta-Analysis. Personality and Individual Differences, 82, 26-33.

Knaus, W.J. (2000). Procrastination, Blame and Change [Special issue]. Journal of Social Behavior and Personality, $15,153-166$.

Lavoie, J.A.A. ve Pychyl, T.A. (2001). Cyberslacking and the Procrastination Superhighway: A Web-Based Survey of Online Procrastination, Attitudes, and Emotion. Social Science Computer Review, 19(4), 431-444.

Lay, C.H. (1986). At Last My Research Article on Procrastination. Journal of Research in Personality, 20, 474-495.

Lee, K.S. ve Tan, S.J. (2003). E-retailing Versus Physical Retailing: A Theoretical Model and Empirical Test of Consumer Choice . Journal of Business Research, 56(11), 877-885.

Li, S. ve Chatterjee, P. (2005). Shopping Cart Abandonment at Retail Websites-A Multi-stage Model of Online Shopping Behavior. Available at: http://elab.vanderbilt.edu/ Research_papers.

Mahnke, R., Benlian, A. ve Hess, T. (2014). Flow Experience in Information Systems Research: Revisiting its Conceptualization, Conditions, and Effects. ICIS 2014 proceedings. 
McCown, W. ve Johnson, J. (2012). Validation of an Adult Inventory of Procrastination. New York: Society for Personality Assessment.

Negra, A., Mzoughi, N. ve Bouhlel, O. (2008) . E-procrastination: A Netnographic Approach. Journal of Customer Behaviour, Vol. 7 No. 2, pp. 103-109.

Novak, Thomas P., Hoffman, Donna L., Yung, Yiu-Fai (2000) . Measuring the Customer Experience in Online Environments: A Structural Modeling Approach. Marketing Science, 19 (1), 22-42.

O'Cass, A. ve Carlson, J. (2010). Examining the Effects of Website-Induced Flow in Professional Sporting Team Websites. Internet Research, 20(2), 115-134.

Peter, J.P. ve Tarpey, L.X. (1975). A Comparative Analysis of Three Consumer Decision Strategies. Journal of Consumer Research, 2: 29-37.

Ringle, C.M., Wende, S. ve Becker, J.M. (2015). SmartPLS 3. www.smartpls.com.

Sabini,J. ve Silver M. (1981). Procrastinating. Journal for the Theory of Social Behaviour, pp. 207-221.

ScanAlert (2005). A New Era of Digital Window Shopping: from Shopping Cart Abandonment to Purchase. www.webhostgear.com/shopping_habits.pdf.

Seock, Y. ve Bailey, L.R. (2008). The Influence of College Students Shopping Orientations and Gender Differences on Online Information Searches and Purchase Behaviors. International Journal of Consumer Studies, 32, 113-121.

Shang ,R.A., Chen Y.C. ve Shen, L. (2005). Extrinsic versus Intrinsic Motivations for Consumers to Shop Online. Information Management, pp. 401-413.

Shaw, N. ve Sergueeva, K. (2019). The Non-monetary Benefits of Mobile Commerce: Extending UTAUT2 with Perceived Value. International Journal of Information Management, 44-55.

Solomon, L.J. ve Rothblum, E. D. (1984). Academic Procrastination: Frequency and Cognitive-Behavioral Correlates. Journal of Counseling Psychology, 31 (4), 503-509.

Thakur, R. ve Srivastava, M. (2014). Adoption Readiness,Personal Innovativeness, Perceived Risk and Usage Intention across Customer Groups for Mobile Payment Services in India. Internet Research, 24(3), 369-392.

Thatcher, A., Wretschko, G. ve Fridjhon, P. (2008). Online Flow Experiences, Problematic Internet Use and Internet Procrastination. Computers in Human Behavior, 24, 2236-2254. doi:10.1016/j.chb.2007.10.008. 